Trieste

\title{
POÉTICA Y PRÁCTICA EN PABLO NERUDA
}

0. El debate sobre la muerte de las ideologías, enriquecido por los acontecimientos del este europeo, actualiza, asimismo, algunos problemas que hacen a las relaciones entre el escritor y la sociedad. Introduce, si no más, la posibilidad de alguna perspectiva cambiante o de un ajuste de cuentas, cuando no de alguna corrección crítica o de alguna nueva lectura de ciertos autores. Pablo Neruda es uno de aquellos nombres que brinda un campo propicio para una reflexión crítica, tanto sobre la actitud del poeta frente al propio trabajo cuanto sobre sus relaciones con la sociedad y el mundo circundante. Buena parte de sus opiniones al respecto, aparecen en sus memorias, texto prevalente para nuestro trabajo.

Algunas afirmaciones del propio Neruda parecen orientadas, sin embargo, a disuadirnos de esta reflexión crítica, más aún si se piensa en la rica bibliografía existente sobre el autor. En un fragmento de sus memorias - el que se ocupa de Radomiro Tomic - aparecen estas afirmaciones, situadas alli como un enclave:...tengo una indiferencia natural hacia los teorizantes de la poesía, de la política, del sexo ${ }^{1}$. De un modo más o menos explícito y tajante lo ha dicho y escrito otras veces. Es el tema, además de su Oda a la crítica. Estas afirmaciones, que por su peso no aparecen de ningún modo como circunstanciales, oponen, de manera explícita, una práctica a una teoría poética (en sus reflexiones no se vislumbra la posibilidad de un concepto como el de práctica teórica) y constituyen un punto de partida casi insoslayable para quien se decide a enfrentar problemas candentes de la poética nerudiana.

1. Verificar en la obra de Neruda los pasos del proceso que caracterizó políticamente la poética del realismo socialista es casi una tentación y parece suponer una primera aproximación crítica, si bien esquemática y parcializada. De aquí, el camino nos llevaría a considerar, por una parte, su obra de compromiso político, como dictada por los lineamientos de dicha poética, $\mathrm{y}$, por otra, su obra antidogmática. Tal visión privilegiaría, en la actualidad, esta última vertiente, impulsada por una vocación que habría restituido a la poesía su lugar preciso y su autonomía. En este sentido, no deja de ser curioso, e interesante además para el estudio de las relaciones entre la poesía y sus referentes temáticos, que un escritor, aparentemente en las

1 Confieso que he vivido. Memorias, Barcelona, Seix Barral, 1974, p. 471. 
antípodas de Neruda, como lo era Jorge Luis Borges, haya señalado que En su etapa sentimental, Pablo Neruda era un poeta muy flojo. Cuando se dejo llevar por el comunismo, escribió espléndidos poemas. Él necesitaba ese estímulo, aunque yo, como lector suyo, no lo necesito ${ }^{2}$. Menos sorprendente es que Althuser recuerde que Las sociedades humanas secretan la ideología como el elemento indispensable a su respiración, a su vida histórica. Sólo una concepción ideologica del mundo pudo imaginar sociedades sin ideologías... ${ }^{3}$. En el caso de Neruda, aquella primera y esquematizada aproximación crítica constituye un punto (que conlleva su propia destrucción al mismo tiempo) a partir del cual podrá verse que su obra reviste un carácter orgánico, con etapas que, lejos de excluirse se integran, a veces complementándose, otras a través de una relación dialéctica.

2. Inserta en la índole misma de la tradición poética, ligada en buena parte a sus orígenes, la concepción de la poesía como servicio, es un aspecto insoslayable en Neruda y adquiere una importancia sustancial. Al hablar de vocación de servicio en el campo de la poesía no pensamos aquí en quienes, siendo poetas, han integrado su creación a un gesto humano y político extremo, como el de morir por una causa, de lo cual constituyen testimonios elocuentes Javier Heraud, Miguel Ángel Bustos, Roque Dalton, Francisco Urondo, entre otros. Tampoco pensamos en quienes han consagrado su vida a la poesía, que se han declarado dispuestos a morir por la misma o en quienes no podrían vivir sin ella, todos prisioneros por igual de una alienación que sacrifica aspectos humanos sustanciales. Pensamos, más bien, en una actitud más modesta y menos heroica, en esa vocación de servicio - de la cual tampoco están excluidos los poetas mencionados - que se ejerce en la práctica de la poesía, a través del trabajo de la palabra. Recuerda Neruda que En buena parte de mi obra he querido probar que el poeta puede escribir sobre lo que se le indique, sobre aquello que sea necesario para una colectividad humana. Casi todas las grandes obras de la antigüedad fueron hechas sobre la base de estrictas peticiones. Las Geórgicas son la propaganda de los cultivos del agro romano. Un poeta puede escribir para una universidad o un sindicato, para los gremios y los oficios. Nunca se perdió la libertad con eso ${ }^{4}$. Para reafirmar su adhesión a una poética del servicio, Neruda contrapone la noción de trabajo, de oficio de la poesía, ligado por otra parte a una concreta tradición cultural y lingüística, a la concepción del ángel, del poeta mediumnímico: La inpiración mágica y la comunicación del poeta con Dios son invenciones interesadas. En los momentos de mayor trance creador, el producto puede ser parcialmente ajeno, influido por lecturas y presiones exteriores $^{5}$. La cita es importante por lo que dice, pero más aún por el cambio

2 Esteban Peicovich, Borges, el palabrista, Madrid, Letras Viva, 1980, p. 195.

3 L. Althuser, La revolución teórica de Marx, México, Siglo XXI, 1967, p. 192.

4 O. C., p. 370. 
brusco, el contrapunto que le sigue: De pronto interrumpo estas consideraciones un tanto teóricas y me pongo a recordar la vida literaria de mis años mozos... ${ }^{6}$. Manifiesta así, como lo hará a menudo, su hastío por la teorización y su inclinación por la práctica, destructora de ideologías, de dogmatismos, práctica que incluye la poesía.

Esta vocación de servicio de Neruda se identifica, de algún modo, con la asunción del papel de intérprete de un pueblo. La conciencia de ser el intérprete autorizado de su pueblo, escribe Giuseppe Bellini, afirmada rotundamente en el Canto General, no sólo en el verso de Amor América: "Yo estoy aquí para contar la historia" sino más claramente aún en el último de los poemas dedicados a las Alturas de Macchu Picchu, donde se proclama voz de los desaparecidos: "Apegadme los cuerpos como imanes./Acudid a mis venas y a mi boca./Hablad por mis palabras y mi sangre", confirma una vez más la función nerudiana de "pueblo y canto" $"$. Esta concepción nerudiana del poeta como intérprete del pueblo comulga, en muchos pasajes de su obra con la noción de poesía como rescate cotidiano. Aquí cabría, tal vez, remitir a la vieja separación entre la acción y el cantor. En la fórmula del Canto General, Yo estoy aquí para contar la historia, no existe tanto una identificación entre pueblo y canto, como, más bien una separación, una división del trabajo en el sentido más lato. Esta contradicción se resuelve, quizás en el campo político de la función del poeta, donde el papel de intérprete, con su sentido de mediación, supone su paulatina extinción en cuanto tal.

Por otra parte, cabría hablar también de un desplazamiento semántico que se produce en ciertos elementos que, formando parte de un sistema de creencias, de una ideología dada, pasan no ya a integrar un nuevo sistema, sino a formar parte de una práctica política. Entre la ideología que intenta mantener un orden establecido con sus jerarquías alienantes, en la que el poeta aparece separado de la producción material y en una condición privilegiada, y la práctica política del poeta en función de ruptura, residiría tal desplazamiento. Tal vez los deberes del poeta, escribe Neruda, fueron siempre los mismos en la historia. El honor de la poesía fue salir a la calle, fue tomar parte en éste y en el otro combate. No se asustó el poeta cuando le dijeron insurgente. La poesía es una insurrección. ${ }^{8}$ Recuerda Alain Sicard que Neruda ha combatido durante toda su vida la "inspiración" que consideraba como "una

$5 \quad$ Ibídem, p. 371.

6 Ibídem.

7 G. Bellini, “La poesía pósthuma de Pablo Neruda”, en Coloquio Intemacional sobre Pablo Neruda, Poitiers, Centre de Recherches latino-américaines, 1979, p. 22.

8

o. C., p. 404. 
invención interesada": son las cosas y los hombres que, desde fuera, desde la historia, exigen del poeta que los cante ${ }^{9}$.

3. La poesía es un oficio, un trabajo. Pero como lo recuerda Sicard, si bien la noción de trabajo es el eje en torno al cual funda su quehacer poético, la relación con el mundo de la producción material no siempre es la misma en Neruda. Así, por ejemplo, en El hombre invisible hay una identificación del poeta con el mundo de los productores, mientras que, por ejemplo, en Las manos del día, el poeta se siente excluido del trabajo humano. ${ }^{10}$ En este último caso vuelve a plantearse, pues, la separación entre el trabajo manual y el trabajo intelectual. Sin embargo, es posible ver aquí dos planos diferentes; el primer caso nos brinda elementos para una poética de Neruda, que es la inserción misma de la noción de trabajo indiferenciado en la poesía; el segundo caso hace más al campo de las relaciones sociales y económicas. En cuanto a aquel primer caso, cabría recordar que más de un teórico ha mantenido la distinción entre producción y creación para poner de relieve que también en la producción industrial interviene la creación. Más que la reducción de la creación al término único de producción, bastante preciso cuando se refiere al trabajo físico, la reducción del abismo que separa el trabajo físico del intelectual se hace más evidente cuando se reconoce cuánto hay de creación en el trabajo del obrero. Es evidente que aquí (Sicard se refiere al poema Destinos), está sugerida una finalidad particular de la actividad poética que reintegra ésta, más allá de las separaciones impuestas por la división social del trabajo a la generalidad de las producciones humanas. ${ }^{11}$ Esta concepción nerudiana está presente también en lugares inesperados por el lector:...es fácil darse cuenta que aún en este universo aparentemente ahistórico de las Residencias, hay ya un conato, un germen premonitorio del trabajo humano como forma privilegiada de creación: "Con mi razón apenas, con mis dedos" que no expresan desde luego una complacencia sensual, un mero tacto, sino una penetración transformadora, pre-instrumental ${ }^{12}$.

Instaurar la noción de trabajo en la poesía implica considerar la misma como una forma de transformación del mundo. Frente a la vieja concepción del arte como imitación, la poesía nerudiana asume un papel de activación del lector, de

9 Alain Sicard, "El hijo de la luna: crítica y valoración del sujeto poético en la obra de Pablo Neruda posterior al Canto General", en Coloquio Internacional sobre Pablo Neruda, p. 324.

10 Ibidem, p. 334.

11 A. Socard, O. C, p. 335.

12 J. Concha, "Neruda, desde 1952: 'No entendí nunca la lucha sino para que ésta termine", en Coloquio Internacional sobre Pablo Neruda, p. 74. 
participación crítica y descubrimiento de aspectos de la realidad, de ideas y comportamientos que no se integran en un sistema pasivo (ni eterno). La poesía descubre contradicciones, en las cuales ella misma está inmersa, y su práctica constituye, a menudo, su doloroso cuestionamiento. El trabajo poético, asumido como tal no puede sino ser antidogmático y crítico.

La noción de trabajo, con vistas a una poética, asume una índole diferente de cuando la misma se refiere a la separación entre el trabajo manual y el intelectual. Así, por ejemplo, privilegiar o requerir un status profesional - contra el cual obviamente no estamos - conduce a la paradoja de acentuar la separación, de convertir la poesía en espectáculo donde unos pocos actúan y, en el mejor de los casos, otros hacen de espectadores. En Las manos negativas, Neruda vive este conflicto: no sólo la impotencia, la inutilidad de no producir materialmente, sino el desamparo y el no saber qué hacer con este otro tipo de actividad. La poesía - como nos autoriza a entenderla buena parte de la obra de Neruda - es inseparable del hombre, casi un derecho natural, una práctica vital que no se ejercerá solo en la instancia de la escritura y que, como la lengua, - que jamás ha podido ser considerada exclusivamente como una superestructura - forma parte de la actividad productora del hombre en su transformación del mundo. En las condiciones actuales de desarrollo de la sociedad, el trabajo poético, en tanto que práctica no integrada, si no se reivindica ideologicamente puede ser asumido políticamente para ir minando las bases de una concepcion que postula la separación entre el trabajo intelectual y el físico.

4. En su proceso transformador, la poesía ha contribuido a dar una nueva dimensión al concepto de cotidianeidad, ligado de tantos modos, a la noción de trabajo. La inspiración, que convertía al poeta en instrumento de los dioses, no podía sino poseer un corpus - valga la paradoja - selecto y bien delimitado de palabras. En oposición a la vida heroica y de los sueños en el clasicismo y en el romanticismo, la cotidianeidad ha sido propuesta para esta poética no como el espacio donde residen los heroísmos y los sueños, sino como un polo opuesto a éstos. De ahí que tampoco aparezca como el espacio de la poesía, ni pueda ser insertado con dignidad en la misma. La práctica poética de Neruda no comulga con esta estrechez del concepto de cotidianeidad. Porque comparé unas piedras con unos patitos, un crítico uruguayo se escandalizó. Él habia decretado que los patitos no son material poético, como tampoco otros pequeños animales. ${ }^{13}$ Los ejemplos en que esta cotidianeidad se convierte en el único espacio posible para Neruda son numerosos; su poesía en primer lugar, sus

O. C., p. 406 . 
declaraciones explícitas. Otro tanto cuando quiere indagar en el trabajo: Para buscar lo indefinible, la guía o el hilo que une el hombre a la obra, hablo de aquellos que tuvieron algo o mucho que ver conmigo. Vivimos en parte la vida juntos y ahora yo los sobreviva. No tengo otro medio de indagar lo que se ha dado en llamar el misterio poético y que yo llamaría la claridad poética. Tiene que haber alguna relación entre las manos y la obra, entre los ojos, las vísceras, la sangre del hombre y su trabajo. Pero yo no tengo teoría. No ando con un dogma debajo del brazo para dejarselo caer en la cabeza a nadie ${ }^{14}$. Hablar de rescate de la poesía a partir de la vida cotidiana implica reconocer la naturaleza metaforica de la lengua. La metáfora, por indicar sólo uno de los procedimientos más recurrentes de la poesía no es sino el procedimiento fundamental de la lengua para autoalimentarse, recrearse y transformarse de continuo; toda palabra es, por naturaleza, un elemento metafórico. Para Neruda se trata, sobre la base de una poética del recate, de descubrir, incluso, la propia estructura del discurso poético en los pliegues del lenguaje cotidiano, computando, además, que la poesía no se agota con la lengua. Hay, en la poética nerudiana, como una intención de regresar a esa relación de tipo mágico - en el sentido antropológico de la palabra - en que el nombre y el referente son una única cosa, ya inseparable.

Este espacio de la cotidianeidad abarca aspectos de la poesía nerudiana que han sido objeto de discusión, como, por ejemplo, la soledad. Recuerda Alain Sicard que La soledad no es para Neruda el contrario antinómico de la historia en la medida en que, como esta última, tiene como efecto la momentánea negación del individuo en una realidad objetiva que por todas partes lo sobrepasa. La soledad nerudiana es un momento de la dialéctica: aquel cuando la historia rompe con su propia negatividad, la niega sumergiéndose en el mundo natural para confirmarse en sus origenes naturales ${ }^{15}$. Para Neruda, la cotidianeidad es la única dimensión posible; la otra vida es ideología, sea reflejo, sea expresión. La explícita o implícita determinación de otra existencia posible - real o sobrenatural - no se integra con la poesía de Neruda. Lo que aparece es justamente la lucha, o la no lucha - si queremos denominar así los momentos de nihilismo o de impotencia frente a la realidad -, lucha o no lucha que no puede ser más que cotidiana, sujeta a condiciones que determinan, a al menos explican, la actitud y el tipo de acción y naturalmente la poética de un autor. Al decir que no aparece en Neruda, nos referimos a aquel espacio que se constituye como sistema de representaciones, y en este caso la ideología que tiende a mantener un status quo como la ideología revolucionaria aparecen igualmente extrañas.

14 Ibídem, p. 392.

15 A. Sicard, “Soledad, muerte y conciencia histórica en la poesía reciente de Pablo Neruda”, en Simposio Pablo Neruda. Actas, Columbia, University of South Carolina, 1975, p. 162. 
Esta relación definitoria con la cotidianeidad - tanto en lo que atañe a su actitud frente al trabajo poético como a aspectos vitales - tiene su correspondencia, asimismo, cuando Neruda aborda las condiciones de vida del poeta. También aquí lo vemos reaccionar contra algunos lugares comunes o modelos, ligados a concepciones de circunstancia. El poeta debe torturarse y sufrir, debe vivir desesperado, debe seguir escribiendo la canción desesperada. Esta ha sido la opinión de una capa social de una clase. Esta fórmula lapidaria fue obedecida por muchos que se doblegaron al sufrimiento impuesto por leyes no escritas, pero no menos lapidarias. Estos decretos invisibles condenaban al poeta al tugurio, a los zapatos rotos, al hospital y a la morgue. ${ }^{16}$ Para hacer más clara su idea, Neruda condena el estereotipo que quiere la alegría como un aspecto superficial o soslayable de la vida. Los poetas tienen derecho a ser felices, sobre la base de que estamos férreamente unidos a nuestros pueblos y a la lucha por su felicidad. ${ }^{17} \mathrm{O}$ aboga por un hombre total, contradictorio en el mejor sentido nietzscheniano: ....un hombre claro y confundido, /.../ un hombre lluvioso y alegre,/ enérgico y otoñabundo, rezan estos versos de Testamento de otoño de Extravagarios.

5. En un tiempo de profundos ajustes de cuentas, de desmitificaciones, de lucha contra todo dogmatismo, aparece también el peligro de convertir esta apertura en un nuevo dogmatismo; en pocas palabras, de incurrir en el error que se intenta censurar. Querríamos llamar la atención aquí sobre algunos prejuicios, bastante frecuentes, con los cuales convive un cierto tipo de crítica - pienso, sobre todo, en la latinoamericana, pero no sólo -. Tal vez con más vehemencia que nunca - sobre todo a partir del ajuste de cuentas con la poética del realismo socialista - una poética contraria ha venido poniendo limitaciones siempre mayores a la poesía que afronta de un modo decidido el compromiso político y social. Las consecuencias de estas limitaciones se ven en la crítica cotidiana de los periódicos y revistas; los apresuramientos en declarar que si bien poesía inmediata, etc., etc., no se trata de un panfleto equivale a decir que un resto de poesía hay y que ese resto pertenece por lo común a una noción sacralizada de la poesía. Claro que después, en tren de llevar a fondo el problema resultará difícil - tanto desde el punto de vista histórico cuanto epistemológico - separar "verdadera" poesía de la que no lo es. Pienso que es este tipo de poética - identificado del mejor modo con las concepciones vigentes - la que ha llevado a privilegiar - en algunos discursos críticos sobre la obra nerudiana aquella parte de la misma consagrada a los grandes problemas del hombre, etc., o al juego, etc., frente a los mensajes circunstanciales, inmediatos, cotidianos. Creemos que hablar de poesía política y aceptar su circunstancialidad (iexiste alguna poesía eterna?), no debe necesariamente implicar un juicio de valor. Aun en nuestros días,

O. C., p. 365 .

17 Ibídem, p. 366. 
la denominación de política para un tipo definido de poesía conlleva una connotación a veces peyorativa que merece ser desenmascarada. Política e inmidiatez son dos conceptos redimensionados por algunas concepciones literarias. Un problema aparte sería el de analizar en qué medida los elementos fundamentales de esta poética de sustracción, que escamotea y oculta, por lo demás, una parte bien considerable de la poesía moderna, puede haber influido en la propia actitud creadora de Neruda, en qué medida pudo haberlo desalentado en más de una empresa. Porque si bien es posible extraer de su obra una línea coherente, con altibajos que parecen reflejar ciertas vacilaciones frente a tal poética, en sus reflexiones sobre su quehacer estas vacilaciones se hacen más notorias.

Naturalmente que los problemas que plantea la producción nerudiana no se agotan en Neruda. Las llamadas obras circunstanciales e inmediatas no se diferencian de las otras por su valor sino por su función poético-política, que es primodialmente de carácter táctico frente al carácter más bien estratégico que asumen las obras, por llamarlas de algún modo, mediatas. Gramsci recordaba que el escritor y el político no se encuentran en la misma longitud de onda; el segundo piensa a corto plazo; el primero a largo. Mucha poesía de carácter político podría encontrarse en la misma relación con otro tipo de poesía, más seguro de posteridad.

6. En sus Memorias, Neruda habla también del poder de la poesía. ¿Pero se trata aquí realmente del poder de la poesía en el sentido en que podría serle caro a Neruda o más bien la comprobación de una cierta mitificación o privilegio del papel del poeta, u otras circunstancias institucionales? No hay en esta relación con el público esa identificación a la que Neruda tiende en toda su obra, sino más bien una suerte de admiración, de nuevo la separación entre el trabajo manual y el intelectual. Es posible que ese tipo de poder, en la medida en que deja de ser cotidiano, en el sentido de una identificación con el mundo circundante, y se constituye más bien en espectacular, sea precisamente la debilidad de la poesía. Neruda visualiza con claridad este problema en otro aspecto conexo al mismo: cuando el lector toma conciencia sobre la pérdida de un contacto directo entre artista y público.... esta publicación de poeta a poeta no me tienta, no me provoca, no me incita sino a emboscarme en la naturaleza, frente a una roca y a una ola, lejos de las editoriales, del papel impreso. La poesía ha perdido su vínculo con el lejano lector... ${ }^{18}$

7. Hombre y poesía son para Neruda dos términos inseparables. Su concepción la convierte en el primero y en el último reducto del hombre. Necesaria al hombre, 
la poesía es descubrimiento de la realidad y convivencia cotidiana con ésta. Constituye para él un fenómeno que, soportado por palabras, va, sin embargo, más allá de las mismas. La inclinación profunda del hombre es la poesía y de ella sálió la liturgia, los salmos y también el contenido de las religiones. El poeta se atrevió con los fenómenos de la naturaleza y en las primeras edades se tituló sacerdote para reservar su vocación. De ahi que, en época moderna, el poeta, para defender su poesía, toma la investidura que le dan la calle y las masas. El poeta civil de hoy sigue siendo el del más antiguo sacerdocio. Antes pactó con las tinieblas y ahora debe interpretar la luz. ${ }^{19} \mathrm{El}$ intérprete de la realidad quiere, así, no ser sólo un testigo de la misma, sino tambien identificarse. Asumir el compromiso político será, para Neruda, al mismo tiempo, una identificación con la realidad que canta.

8. Así como reaccionaba ante las críticas que consideraban inadmisibles la incorporación a su poesía de vocablos carentes institucionalmente de connotación poética, el lenguaje, como instrumento y a la vez materia que trabaja el poeta, escapa a cánones que no estén estrecha y directamente ligados al mundo circundante, en una relación necesaria. Entre americanos y españoles el idioma nos separa algunas veces. Pero sobre todo es la ideología del idioma la que se parte en dos. La belleza congelada de Góngora no conviene a nuestras latitudes, y no hay poesía española, ni la más reciente, sin el resabio, sin la opulencia gongorina. Nuestra capa americana es de piedra polvorienta, de lava triturada, de arcilla con sangre. (...) El idioma español se hizo dorado después de Cervantes, adquirió una elegancia cortesana, perdió la fuerza salvaje que traía Gonzalo de Berceo, del Arcipreste, perdió la pasión genital que aún ardía en Quevedo. (...) Este manantial anterior tenía que ver con el hombre entero, con su anchura, su abundancia y su desborde. ${ }^{20}$ Recala más adelante: Yo tenía que ser yo mismo, esforzándome como las propias tierras en donde me tocó nacer. ${ }^{21}$

Neruda recurre a menudo a la vitalidad como criterio de valoración poética, la incluye como uno de los elementos fundamentales de su poética. El trabajo de lengua que privilegie el artificio de la palabra, es una operación cultural que poco tiene que ver con la fuerza vital de la poesía. La lengua debe volver a sus fuentes, pero para ello debe establecer una suerte de pacto con la escritura: librar a esta última toda su carga mágica de identificación con las cosas, hacer que su carga de mundo haga olvidar su carga de palabra. Se trata, para Neruda, de un trabajo de lengua que no conduzca a la criptografía o a la hiperbolización, es decir que siga el proceso que va de la

19 Ibídem, p. 369.

20 Ibídem, p. 364.

21 Ibídem, 
comunicación elemental a la explotación de los mecanismos posibles de la lengua, a su relativa independización, sino justamente el camino inverso, que desentrañe la ideología oculta, los aspectos represivos, el misterio generador de poder, la capacidad distorsionante, para volver a la fuerza elemental, a la claridad, a la relación mágica entre la palabra y la cosa. La lengua, para él, no está aquí para ocultar, enmascarar, la poesía, ni menos aún privilegiarse a través de la poesía, sino para ser el mecanismo a través del cual la poesía se expresa y con el cual se identifica.

9. La actitud nerudiana frente a la poesía es de claro signo no-aristotélico. El rechazo de las reglas no le impide rescatar y utilizar, para su propia creación, procedimientos caros al clasicismo. Sabe que es la historia, y no el desierto, el campo de la poesía. ¿Quién instituye los versos más cortos o más largos, más delgados o más anchos, más amarillos o más rojos? El poeta que los escribe es quien lo determina con su respiración y con su sangre, con su sabiduría y su ignorancia, porque todo ello entra en el pan de la poesia. ${ }^{22}$ Neruda se sirve de procedimientos poéticos también tradicionales, pese a pertenecer a la vanguardia; y cuando los rechaza, su actitud parece ser más de desobediencia que de ruptura.

Tal vez no quepa mejor corolario para el presente trabajo que estas palabras suyas: Me place el libro, la densa materia del trabajo poético, el bosque de la literatura; me place todo, hasta los lomos de los libros, pero no las etiquetas de las escuelas. Quiero libros sin escuelas y sin clasificar, como la vida ${ }^{23}$, definitorias de una verdadera vocación antidogmática.

22 Ibídem, p. 368.

23 Ibídem, p. 403. 